\title{
INFLUENCE OF GRAIN REFINEMENT OF HOT BAND AND COLD ROLLING REDUCTION ON THE FORMATION OF TEXTURES AND $R$-VALUE OF COLD ROLLED PLAIN EXTRALOW-CARBON STEEL SHEETS
}

\author{
TAKEHIDE SENUMA* and NATSUKO HASHIMOTO \\ Nippon Steel Corporation, Steel Research Laboratories, 293 Chiba-ken, \\ Futtsu-shi, Shintomi 20-1, Japan
}

(Received 3 June 1997)

\begin{abstract}
A textural analysis was carried out to explain the cause of the planar anisotropy of $r$-value of cold rolled plain extralow-carbon steel sheets. For a detailed analysis, a model for calculating $r$-values from ODF-data of texture was applied and the influence of each or a group of crystal orientations of the recrystallization texture on the planar anisotropy of $r$-values was studied. The following results were obtained:

A development of $\{111\}\langle 110\rangle-\{443\}\langle 110\rangle-\{332\}\langle 110\rangle-\{221\}\langle 110\rangle$ enhanced the $V$ type planar anisotropy of $r$-values. A decrease in the intensity of these orientations by increasing the cold rolling reduction or the refinement of the hot band microstructure reduced the $r$-values in $\mathbf{L}$ and $C$ directions and hardly affected the $r$-value in $D$ direction, and as a result, the V-type planar anisotropy of $r$-values was improved. On the other hand, an increase in the intensity of $\{111\},\{334\}$ orientation by increasing the cold rolling reduction or the refinement of the hot band microstructure raised $r$-values in sequence of $\mathrm{L}<\mathrm{D}<\mathrm{C}$ directions and contributed to the reduction of $\mathrm{V}$-type planar anisotropy of $r$-values as a whole.
\end{abstract}

Keywords: Planar anisotropy; $r$-value; Deep drawability; Extralow-carbon steel; Grain refinement of hot band; Steel sheet

\section{INTRODUCTION}

The ferrite grain size of a hot rolled plain extralow-carbon steel (PELC, extralow-carbon steel without $\mathrm{Ti}$ and/or $\mathrm{Nb}$ addition) is usually

\footnotetext{
*Corresponding author. E-mail: senuma@usuita.re.nsc.co.jp.
} 
relatively coarse, which leads to lowering the mean value of $r$-values and increasing their planar anisotropy. Especially, the large planar anisotropy of $r$-values limits a wide use of PELC steel sheet in practice (Matsudo and Shimomura, 1970). It is well known that the refinement of the hot band microstructure and the increase in the cold rolling reduction reduce the planar anisotropy of $r$-values. However, it is still not clarified by what mechanism the formation of the planar anisotropy of $r$-values is controlled.

To discuss the planar anisotropy of $r$-values, the formation of the textures should be understood. Several researchers have already discussed the influence of the ferrite grain size in hot bands on the formation of cold rolling and recrystallization textures (Matsuo et al., 1971; von Schlippenbach et al., 1986; Emren et al., 1986; Inagaki, 1991). In all the researches, however, the coarse grains were from 150 to $400 \mu \mathrm{m}$ in size which were much larger than the coarse grains in practice, namely $50-70 \mu \mathrm{m}$ in diameter. Therefore, they did not discuss the planar anisotropy of $r$-values which is an important problem in practice.

As Inagaki (1991) reported, if a coarse grain of $400 \mu \mathrm{m}$ is cold rolled, blocks surrounded by shear bands are formed and an independent crystal rotation is performed in each block. The main orientation of the recrystallization texture is $\{110\}\langle 001\rangle$ originated from the recrystallized grains nucleated from the shear bands. This behavior apparently differs from the formation of texture observed in the case of the practical coarse grain in this study.

The grain size of PELC hot bands produced by the usual process is around $50 \mu \mathrm{m}$ and if all means of grain refinement technique are employed, the grain size is approximately halved. In the case of cold rolled PELC deep drawing steel sheets, it is important to use a hot band of grain size below $60 \mu \mathrm{m}$ to discuss the effect of the grain refinement of hot bands on the texture formation and its mechanism.

For this reason, hot bands of 28 and $54 \mu \mathrm{m}$ in grain size were used in this study and the influence of the grain refinement of hot bands and the cold rolling reduction on the formation of texture and the planar anisotropy of $r$-values of cold rolled PELC steel sheets has been investigated by means of a textural analysis to understand the nature of the planar anisotropy of $r$-values which is encountered in practice. 


\section{EXPERIMENTAL PROCEDURE}

In this study, a PECL steel is used whose cold rolled sheet tends to possess a large planar anisotropy of $r$-value. The chemical composition of the steel used is given in Table I. The steel was processed in a $\mathbf{3 0 0}$ ton LD converter. A continuously cast slab $250 \mathrm{~mm}$ thick was reheated at $1250^{\circ} \mathrm{C}$ for $1 \mathrm{~h}$ and hot rolled into a 40 -mm-thick plate. The plate was then machined into smaller plates $40 \mathrm{~mm}$ thick, $150 \mathrm{~mm}$ wide and $200 \mathrm{~mm}$ long. The plates were reheated at $1050^{\circ} \mathrm{C}$ for $60 \mathrm{~min}$ and then hot rolled at a finishing temperature of $950^{\circ} \mathrm{C}$ according to a rolling schedule of $40 \rightarrow 25 \rightarrow 17 \rightarrow 10 \rightarrow 6 \rightarrow 4 \rightarrow 3 \mathrm{~mm}$. The hot rolled bands were subsequently cooled at an average rate of $70-750^{\circ} \mathrm{C} \pm 20^{\circ} \mathrm{C}$ and then placed into an electric furnace at a temperature of $700^{\circ} \mathrm{C}$ and furnace cooled. To produce a fine and coarse ferrite microstructure, a hot rolled band was cooled immediately and another was cooled $1.6 \mathrm{~s}$ after the final rolling.

A hot band was cold rolled to $70 \%, 75 \%, 80 \%, 85 \%$ and $90 \%$. The specimen was annealed at $750^{\circ} \mathrm{C}$ for $120 \mathrm{~s}$ in a salt bath. Subsequently, a skin pass of $1 \%$ was carried out. $r$-values were measured in 3 directions, in the rolling direction $(\mathrm{L}), 45^{\circ}$ inclined to the rolling direction (D) and transverse direction (C). $r_{\text {mean }}$ is defined by $r_{\text {mean }}=$ $\left(r_{\mathrm{L}}+2 r_{\mathrm{D}}+r_{\mathrm{c}}\right) / 4$ while $\Delta r=\left(r_{\mathrm{L}}-2 r_{\mathrm{D}}+r_{\mathrm{c}}\right)$.

The texture was measured using an automatic goniometer with an Mo tube. Detailed studies of the texture were carried out by means of three-dimensional analysis based on the vector method (Ruer and Baro, 1977). The results of texture analysis are described schematically in the form shown in Fig. 1 in which the main crystal orientations appearing in rolling and recrystallization textures can be presented (Shimizu et al., 1989).

For a quantitative comparison of texture formed in different conditions, the intensities of each crystal orientation of one texture determined by three-dimensional analysis are subtracted from the other.

TABLE I Chemical composition of the steel used in the experiment (mass \%)

\begin{tabular}{lcccccc}
\hline $\mathrm{C}$ & $\mathrm{Si}$ & $\mathrm{Mn}$ & $\mathrm{P}$ & $\mathrm{S}$ & $\mathrm{Al}$ & $\mathrm{N}$ \\
\hline 0.0013 & 0.008 & 0.18 & 0.005 & 0.006 & 0.066 & 0.0021 \\
\hline
\end{tabular}




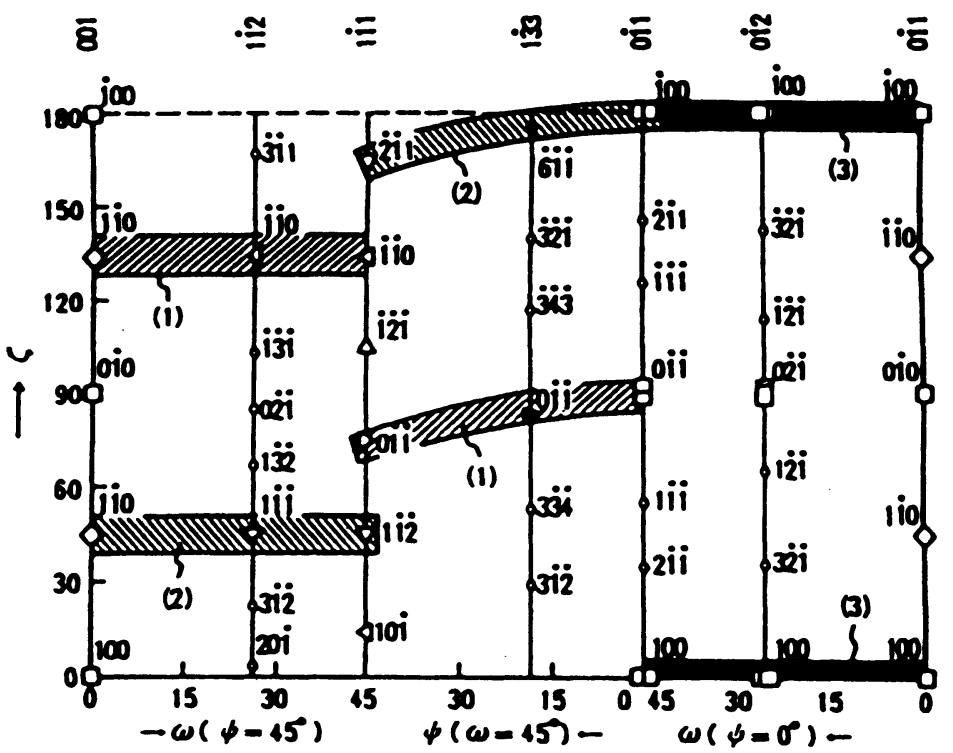

FIGURE 1 Diagram of representative orientations of ODF-data.

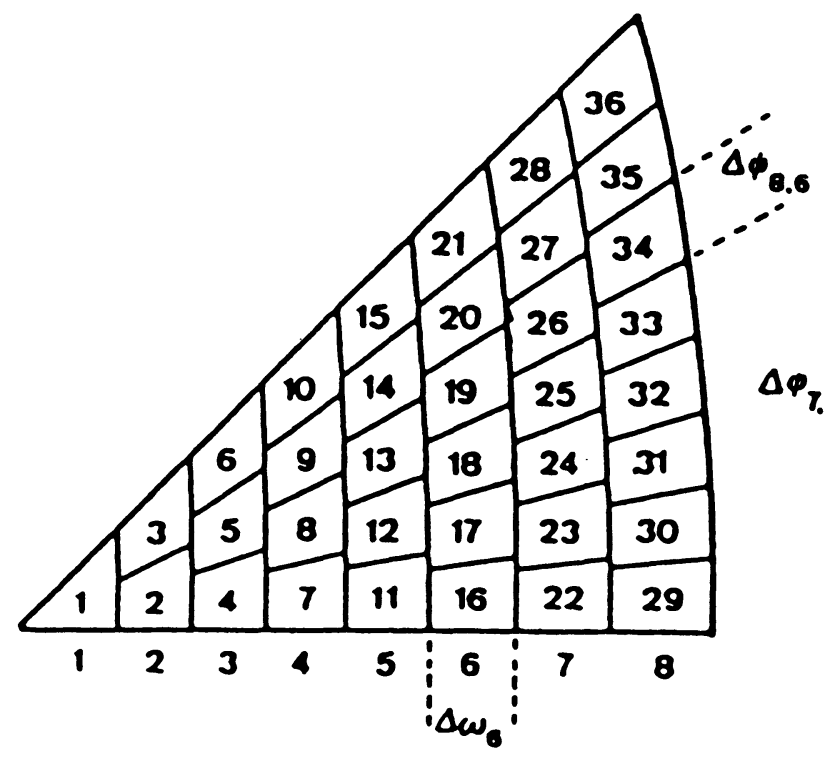

FIGURE 2. Partition of a stereo-triangle. 
The box numbers used for the study on the influence of certain crystal orientation groups on the planar anisotropy of $r$-value were defined as shown in Fig. 2.

\section{EXPERIMENTAL RESULTS}

\section{Influence of Cold Rolling Reduction and Grain Refinement of Hot Band on $r$-values of Cold Rolled Sheets}

Figure 3 shows the microstructure of hot bands in the middle of the thickness. The average grain size of the coarse microstructure $A$ is $54 \mu \mathrm{m}$ and that of the fine one $B$ is $28 \mu \mathrm{m}$. Figure 4 shows the grain size of the cold rolled and annealed sheets of Materials A and B for various cold rolling reductions from $75 \%$ to $90 \%$. The effect of cold rolling reduction on the grain size of the cold rolled and annealed sheets is relatively weak while the grain size of hot band apparently affects it.

Figure 5 shows the hot band textures in the midplane of the thickness of Materials A and B. $\alpha$-fiber $(\{100\}-\{111\}, \mathrm{RD} / /\langle 110\rangle)$ and $\gamma$-fiber $(\mathrm{ND} / /\langle 111\rangle)$ whose development is a feature of a cold rolling texture develop in Material B stronger than in Material A.
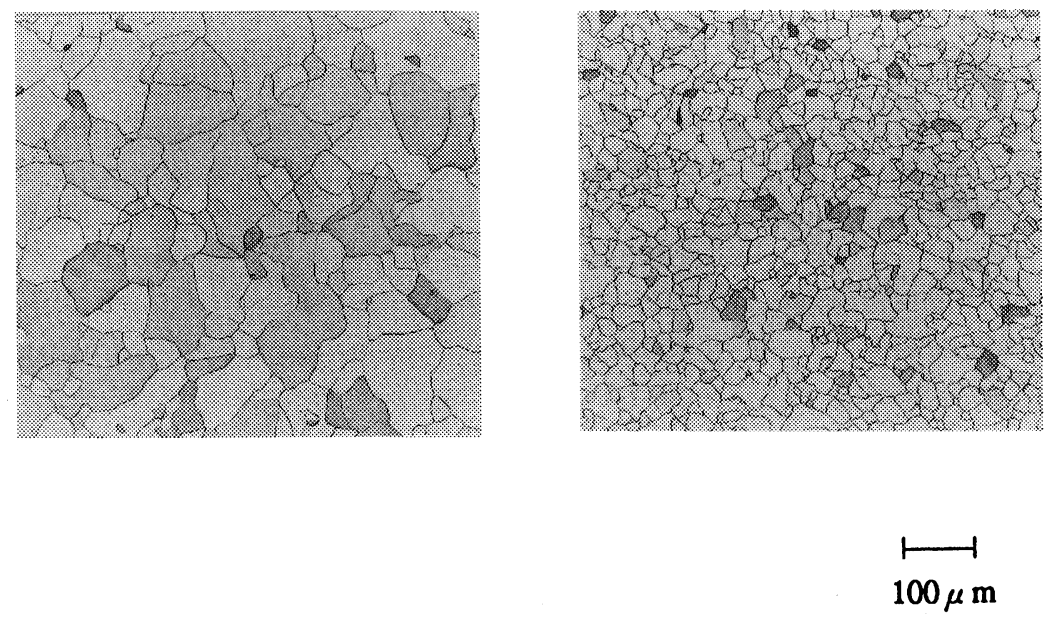

Microstructure of hot bands (left: Material A, right: Material B). 


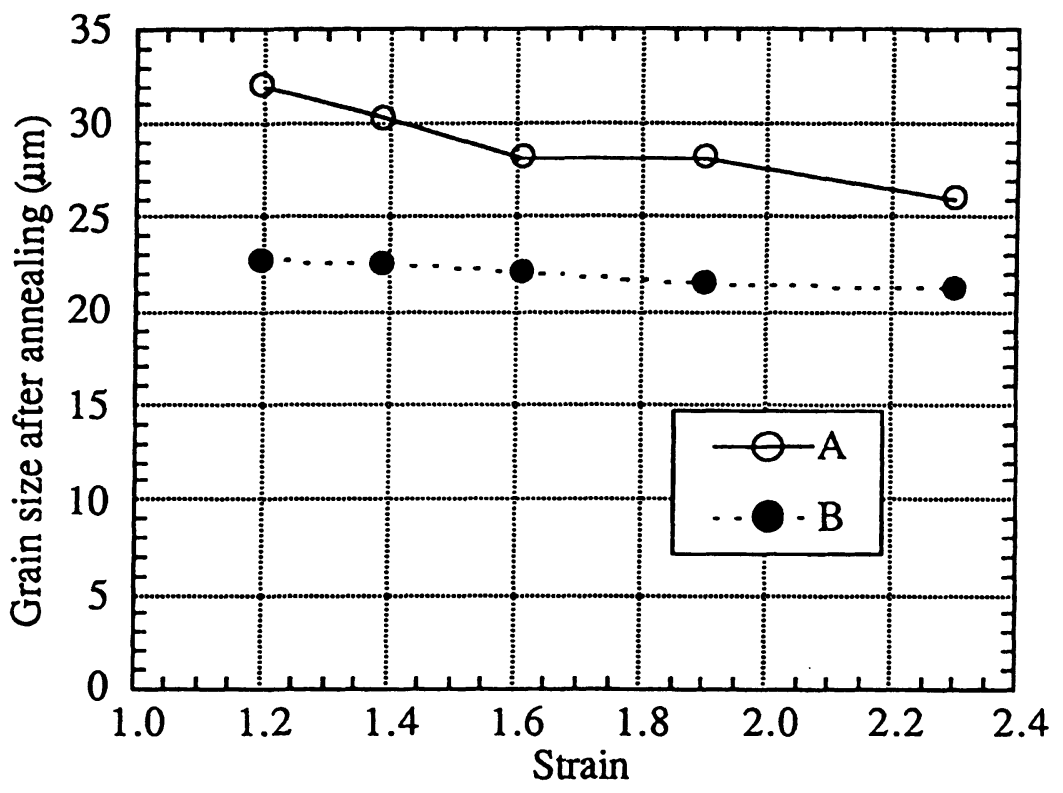

FIGURE 4 Grain sizes of Materials A and B cold rolled at various reduction and subsequently annealed at $750^{\circ} \mathrm{C}$ for $120 \mathrm{~s}$.

Figures 6 and 7 show the $r$-values of cold rolled and annealed sheets of Materials A and B respectively. Figure 8 shows $r$-values and $\Delta r$-values of the two materials. The main findings are summarized as follows:

1. Mean $r$-values increase with increasing cold rolling reduction for both materials and tend to saturate in the high reduction region. $r$-values in the $\mathrm{L}$ and $\mathrm{C}$ directions show a peak at a reduction of 80 $85 \%$ while $r$-values in the $45^{\circ}$ direction increase approximately proportionally to the strain. As a result, the increase in cold rolling reduction from $85 \%$ to $90 \%$ hardly changes the mean $r$-value but significantly reduces the planar anisotropy of $r$-values.

2. Mean $r$-values of Material B are higher than those of Material A at all cold rolling reductions.

3. In this experiment, all the planar anisotropy of $r$-value is characterized as a V type. Larger planar anisotropy of $r$-value is seen in Material $\mathrm{A}$ with a coarser hot band microstructure at any cold rolling reduction. 

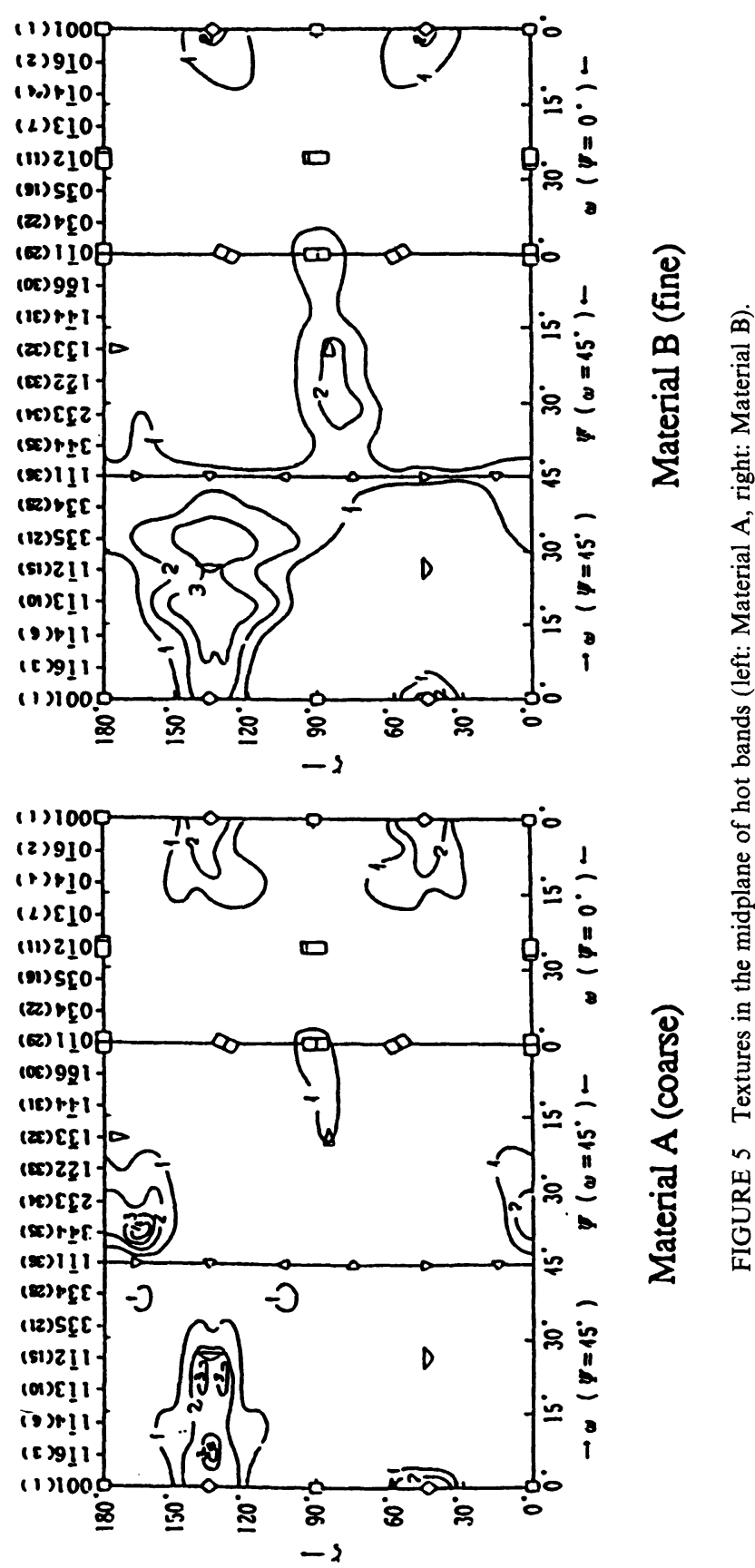


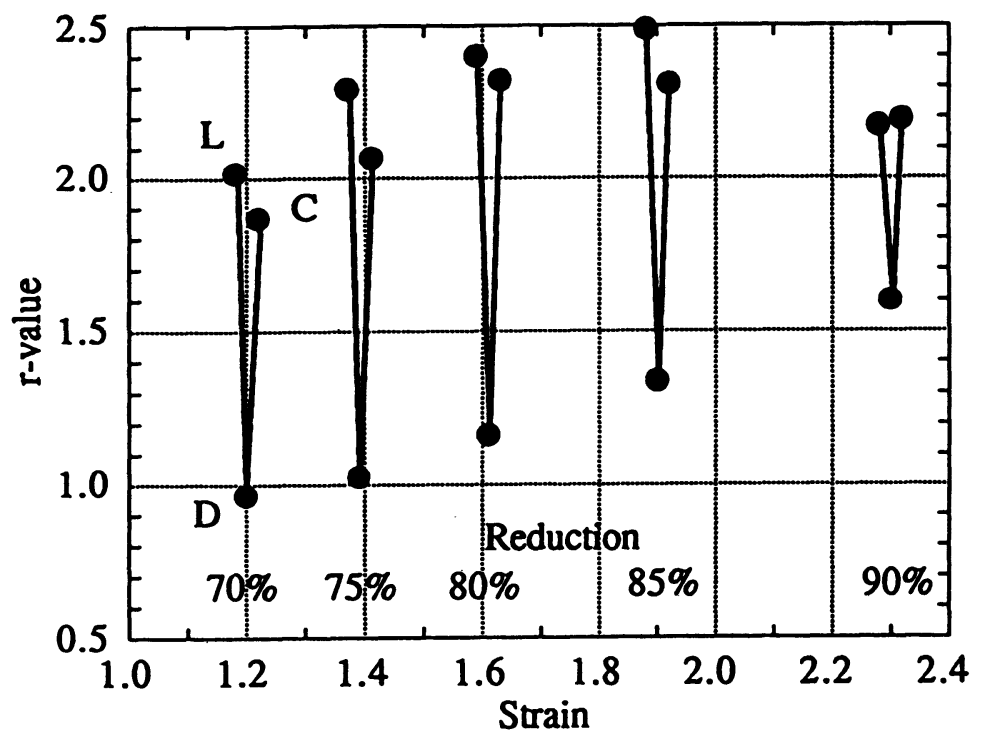

FIGURE $6 r$-value of Material A (coarse hot band microstructure) for the various cold rolling reduction.

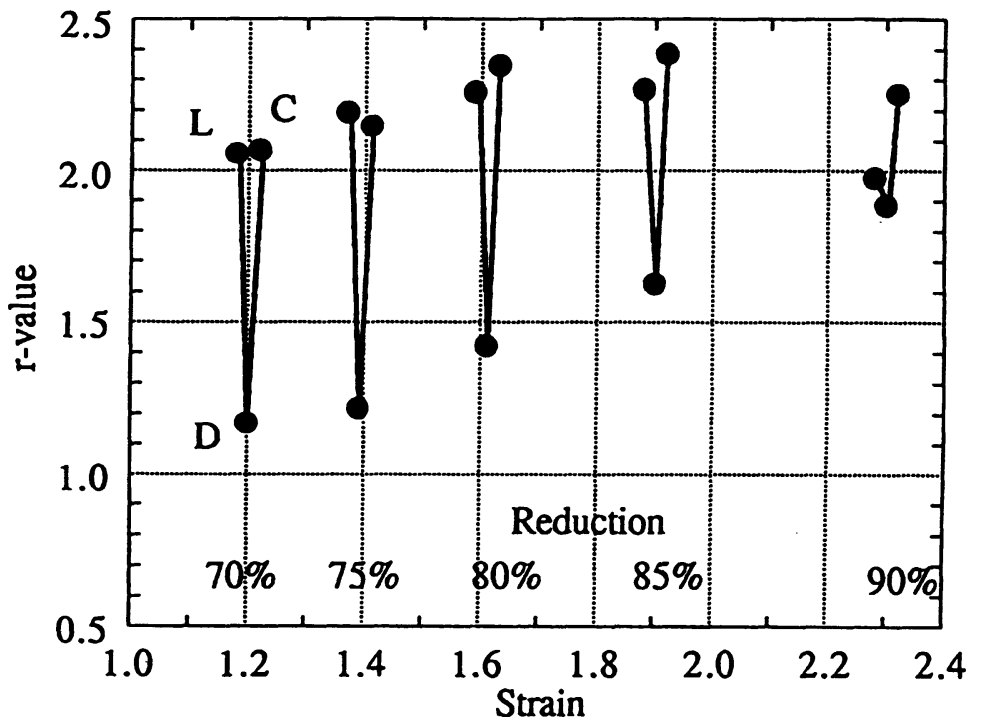

FIGURE $7 r$-value of Material B (fine hot band microstructure) for the various cold rolling reduction. 


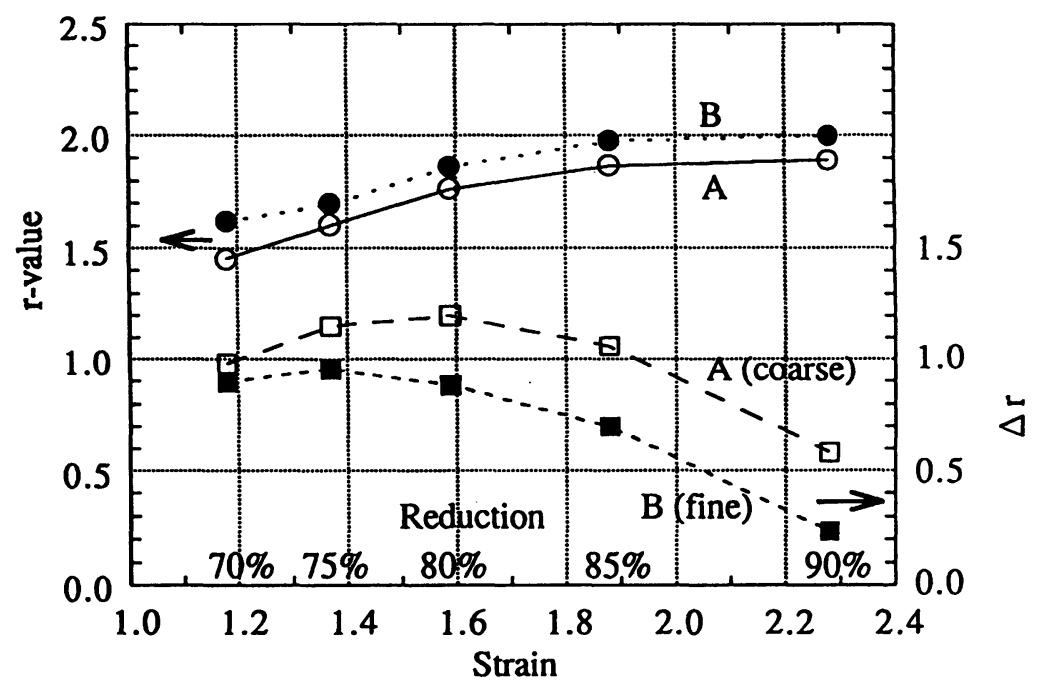

FIGURE $8 r$-value and $\Delta r$-value of Materials A (coarse) and B (fine) for the various cold rolling reduction.

\section{Influence of Cold Rolling Reduction and Grain Refinement of Hot Band on Cold Rolling and Recrystallization Texture}

Figure 9 shows the cold rolling textures of Materials A and B for various reductions. In both materials, $\alpha$ - and $\gamma$-fibers develop with increasing cold rolling reduction. However, the increase in the intensity of $\gamma$-fiber is relatively weak while that of $\alpha$-fiber is apparent. A detailed analysis on the influence of cold rolling reduction on the intensity of $\alpha$ and $\gamma$-fibers of Material B shown in Fig. 10 reveals that the intensity of $\{211\}\langle 011\rangle$ and $\{111\}\langle 112\rangle$ markedly increases with increasing cold rolling reduction.

Figure 11 shows the intensities of $\alpha$ - and $\gamma$-fibers of Materials A and $B$ in cases of $75 \%$ and $90 \%$ cold rolling reductions. The figure reveals that the intensity of $\{111\}\langle 112\rangle$ is higher in the finer grain material while that of $\{111\}\langle 110\rangle$ is higher in the coarser grain material. The figure also shows that $\{100\}\langle 011\rangle \sim\{211\}\langle 011\rangle$ in $\alpha$-fiber develop more in the finer grain material than in the coarser grain material.

Figure 12 shows the difference in intensity of the rolling texture of Material B at $75 \%$ reduction from that at $70 \%$ reduction and the difference in intensity of the rolling texture of Material B at $75 \%$ 


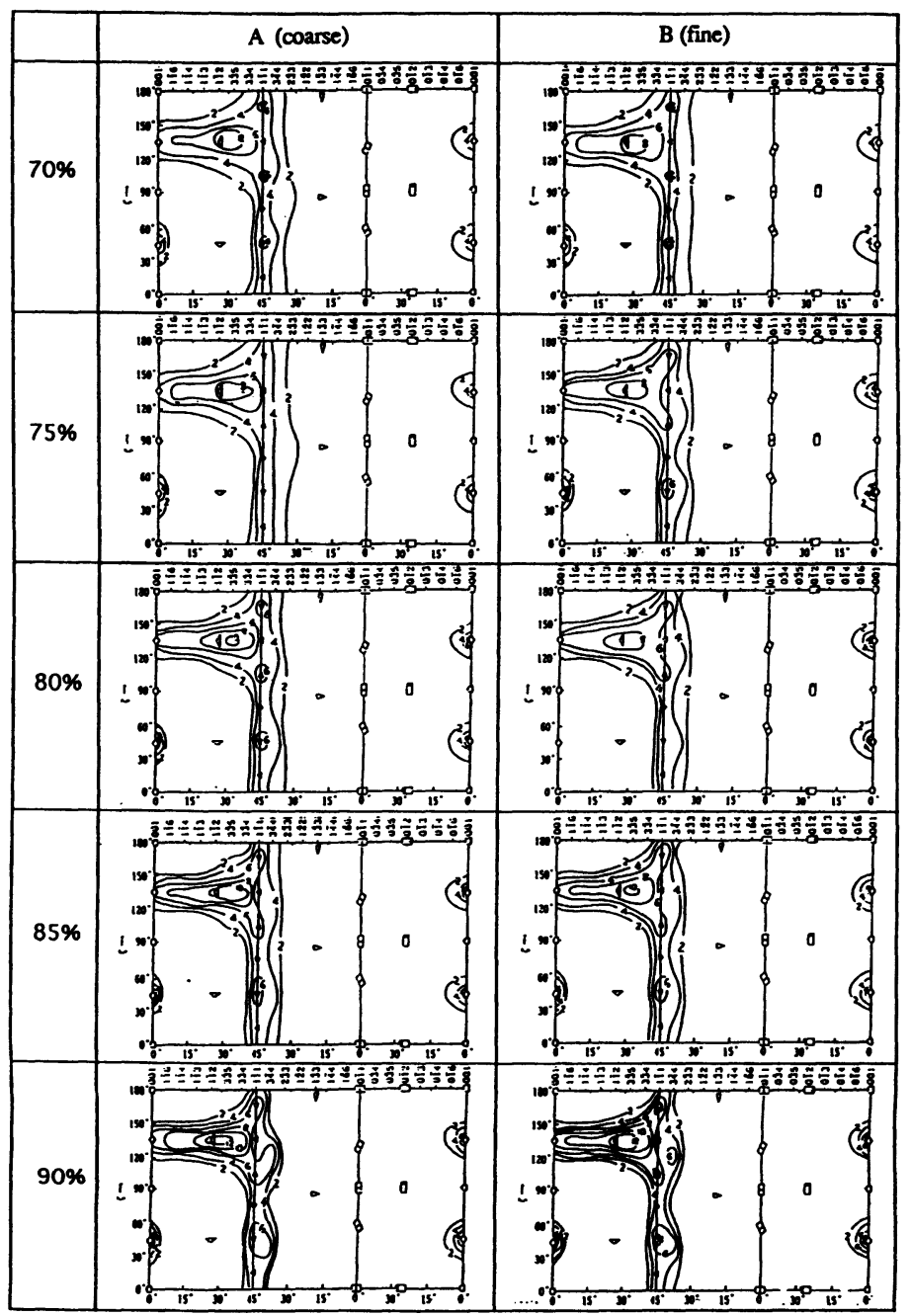

FIGURE 9 Rolling textures of Materials A (coarse) and B (fine) cold rolled to various reductions.

reduction from that of Material A. The solid line and dotted line mean positive and negative iso-intensity line, respectively. The comparison reveals the similarity of the results. It indicates that the effect of grain refinement of hot band on the formation of cold rolling texture is similar to that observed by increasing cold rolling reduction. 


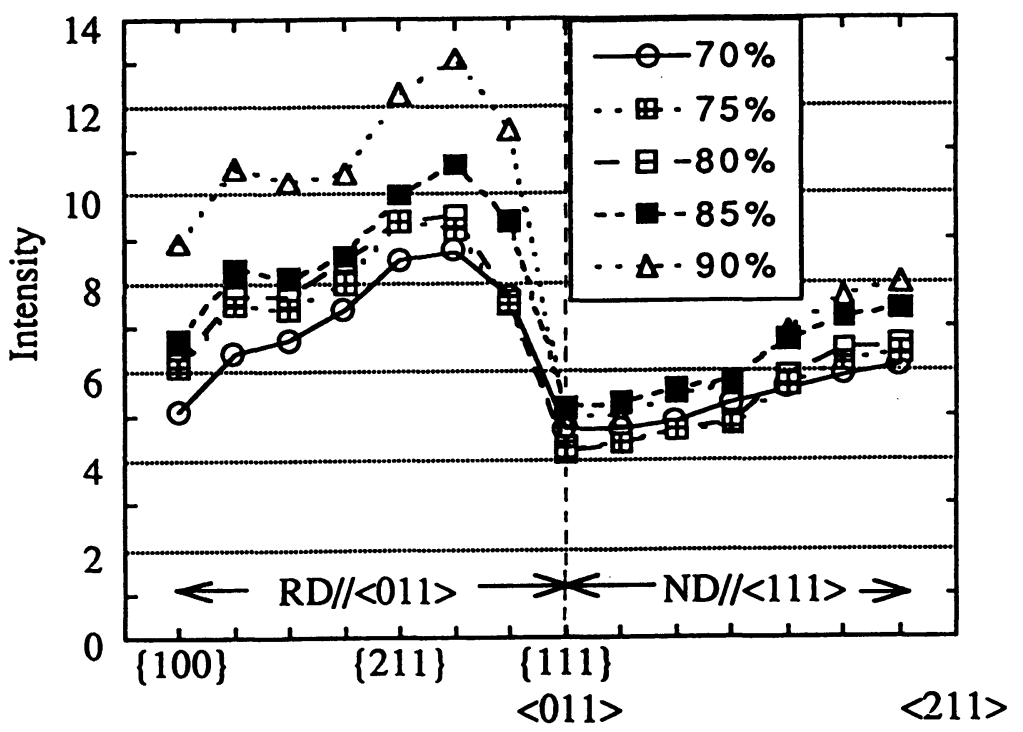

FIGURE 10 Intensities of the orientations in $\alpha$ - and $\gamma$-fibers of the rolling textures of Material B (fine) as a function of the cold rolling reduction.

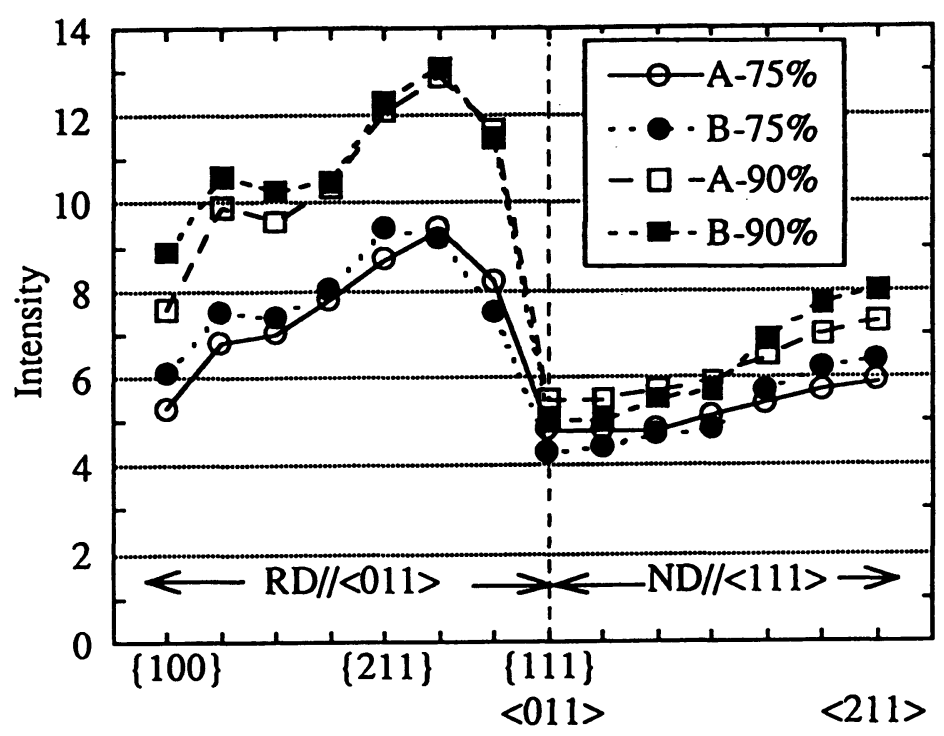

FIGURE 11 Intensities of the orientations in $\alpha$ - and $\gamma$-fibers of the rolling textures of Materials A (coarse) and B (fine) cold rolled to $75 \%$ and $90 \%$. 

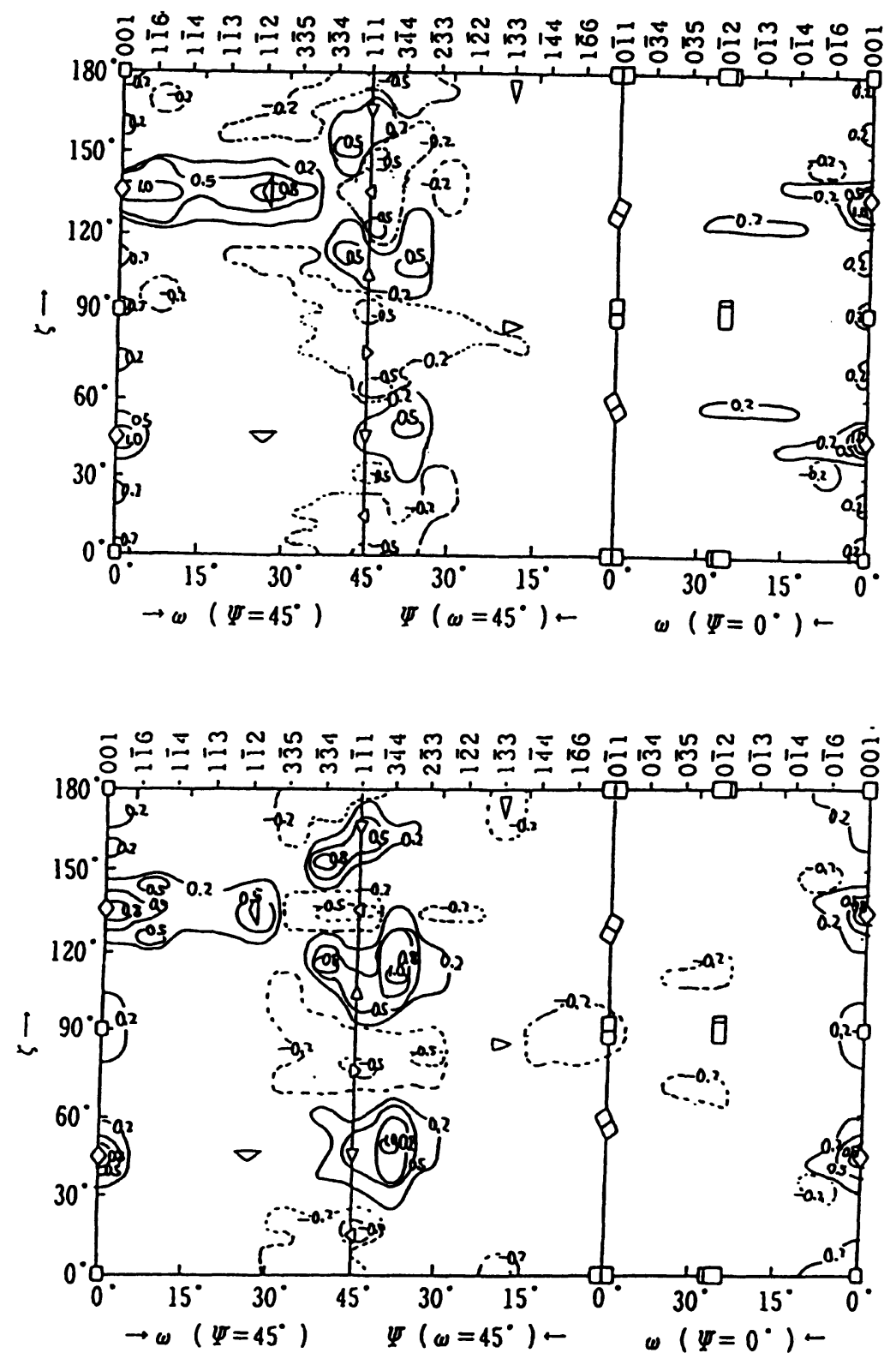

FIGURE 12 Difference of orientation intensities of the rolling textures calculated as: [intensity of Material B (fine) rolled to $75 \%$ - that rolled to $70 \%$ ] (above); [intensity of Material B rolled to $75 \%$ - that of Material A rolled to 75\%] (below). 
Figure 13 shows the recrystallization textures of Materials A and B for various cold rolling reductions. The main orientations are $\gamma$-fiber and they are more developed in the fine grain material at all cold rolling reductions. A remarkable development of $\{110\}\langle 001\rangle$ reported by

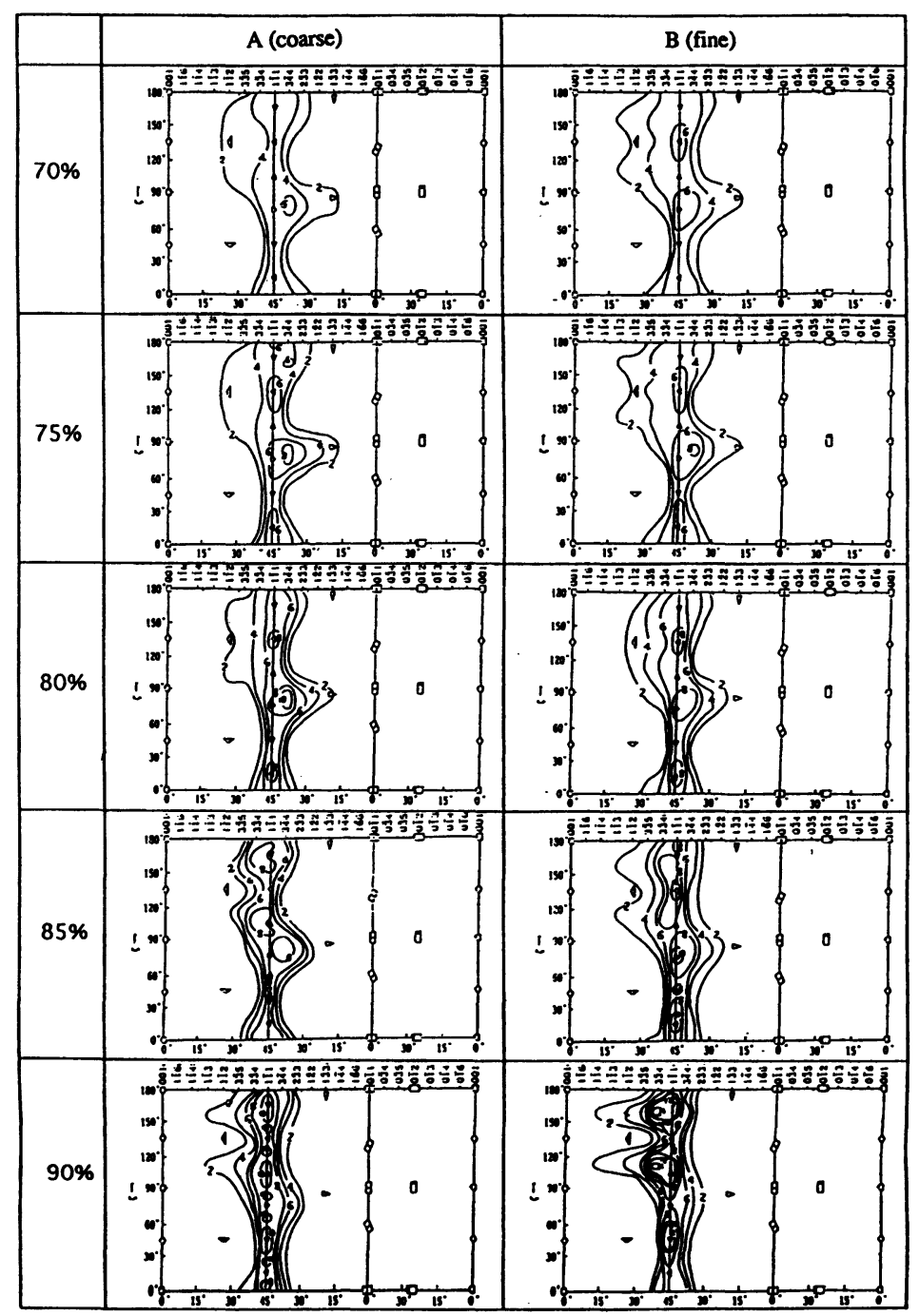

FIGURE 13 Recrystallization textures of Materials A (coarse) and B (fine) cold rolled to various reductions. 
Matsuo et al. (1971) and Inagaki (1991) using hot bands of 300 and $400 \mu \mathrm{m}$ in grain size is not observed in this experiment using a hot band of $58 \mu \mathrm{m}$ in grain size. Up to the cold rolling reduction of $85 \%$, the main orientation is $\{111\}\langle 110\rangle$ and is intensified by increasing the cold rolling reduction. At a cold rolling reduction of $90 \%$, the main orientation changes to $\{111\}\langle 112\rangle$. This change is more clearly observed in the fine grain material.

The orientation group of $\{443\}-\{332\}\langle 110\rangle$ is intensified by increasing the cold rolling reduction up to $80 \%$. This orientation group develops stronger in the coarse grain Material A than in the fine one. They become then relatively weak if the cold rolling reduction increases to $90 \%$. Especially, the decrease in their intensity is apparent in Material B.

The increase in cold rolling reduction leads to a decrease in the intensity of $\alpha$-fiber and an increase in that of $\gamma$-fiber up to $85 \%$ reduction. Further increase in reduction to $90 \%$ results in a remarkable intensification of $\{111\}\langle 211\rangle$ and a decrease of the intensity of $\{111\}\langle 011\rangle$. Transition of the main orientation from $\{111\}\langle 011\rangle$ to $\{111\}\langle 211\rangle$ seemed to occur just at $90 \%$ for Material A while the intensity of $\{111\}\langle 211\rangle$ is much higher than that of $\{111\}\langle 011\rangle$ at $90 \%$ reduction for Material B. It means that the transition occurs at a smaller reduction if the grain size of a hot band is smaller.

\section{DISCUSSION}

\section{Hot Band Texture}

To obtain a fine ferrite microstructure, the onset time for cooling was shortened. Figure 14 shows the softening behavior of the PELC determined by two pass deformation tests. The specimen was $7 \mathrm{~mm}$ in diameter and $12 \mathrm{~mm}$ in height. The experimental procedure and the definition of the softening ratio $x$ is given in the figure. The result indicates that the recrystallization of austenite is completed before $\gamma / \alpha$ transformation if cooling begins $1.6 \mathrm{~s}$ after final rolling while recrystallization hardly proceeded in the case of immediate cooling. The relatively strong development of $\alpha$ - and $\gamma$-fiber of hot rolled Material B is therefore derived from a transformation texture originating from the rolling texture of austenite. 
(a)

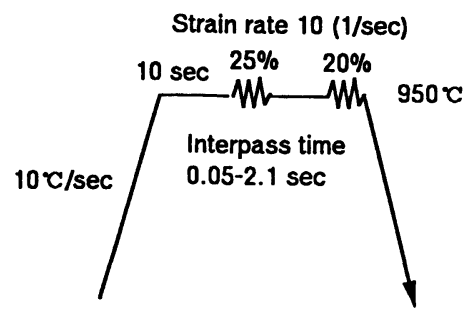

(b)

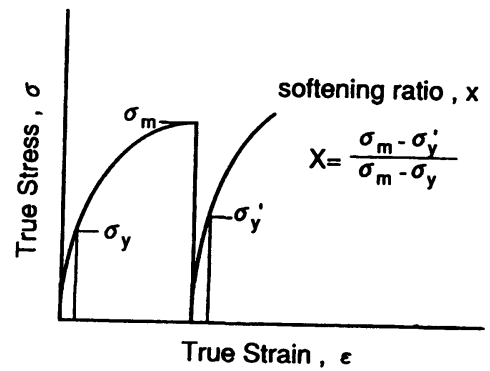

(c)

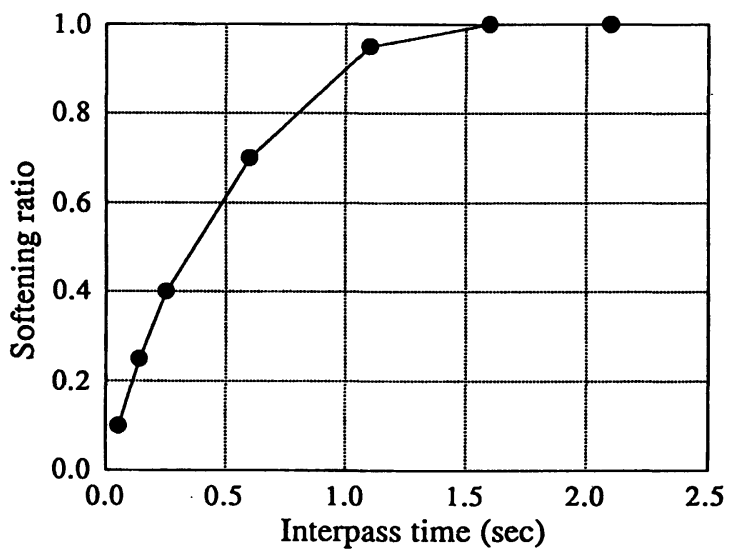

FIGURE 14 (a) Experimental condition of two pass deformation. (b) Definition of the softening ratio. (c) Softening behavior of a PELC steel after a deformation of $25 \%$ at a strain rate of $10 \mathrm{l} / \mathrm{s}$ and a temperature of $960^{\circ} \mathrm{C}$.

\section{Influence of the Grain Refinement of Hot Band on the Formation of a Cold Rolling Texture}

Figure 12 indicates that the grain refinement of hot band has a similar effect on the formation of cold rolling texture as an increase in cold reduction. First of all, the phenomenon can be explained by a strong formation of a transformation texture in the fine grain hot band. As mentioned above, through the grain refinement of hot band, not only the grain size but also the hot band texture was affected. The hot band texture formed by the grain refinement of hot band is similar to the cold 
rolling texture as seen in Fig. 5. It is easily understood that a rolling texture originating from this kind of hot band texture resembles a texture formed in a cold rolled hot band having random texture at a higher reduction.

On the other hand, the grain size of hot band itself may affect the formation of cold rolling texture through an interaction of crystal rotation by grain boundaries. It is quite difficult to get hot bands with different grain size and the same texture. Therefore, to study the effect of hot band grain size on the formation of cold rolling texture, the change in the cold rolling texture from $80 \%$ to $90 \%$ reduction was analyzed in Materials A and B. The results are shown in Fig. 15. These results showed only the difference in intensity between the two materials changed during $10 \%$ reduction from $80 \%$ to $90 \%$ and were hardly affected by their history up to $80 \%$ cold rolling reduction. As seen in the figure, $\alpha$-fiber and a skeleton orientation group from $\{112\}\langle 110\rangle$ to $\{554\}\langle 225\rangle$ which are stable final orientations of cold rolling texture

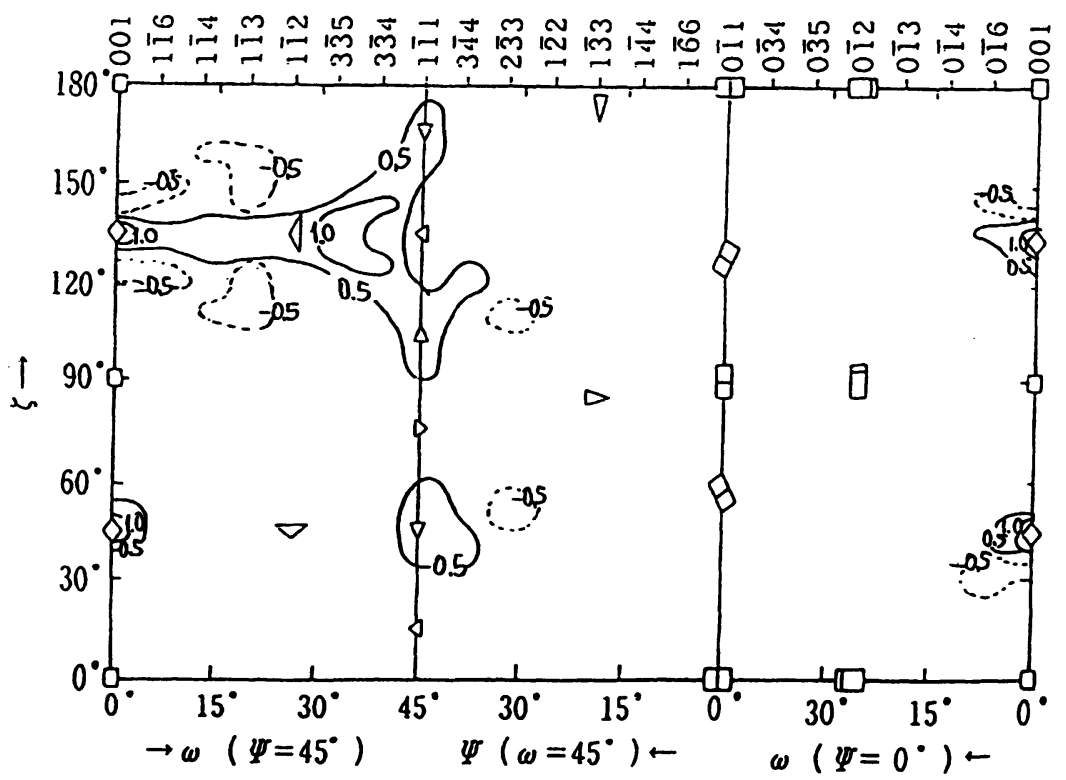

FIGURE 15 Difference of orientation intensities of the rolling textures calculated as: [intensity of Material B after $90 \%$ - that after $80 \%$ ] - [intensity of Material A after $90 \%$ - that after $80 \%]$. 
developed stronger in the fine grain material B than in Material A. It means that if the hot band grain size is smaller, the rolling texture is formed as if the reduction were higher.

In a polycrystalline steel, it is often observed that the crystal rotation in the vicinity of grain boundaries is different from that inside the grain (Abe et al., 1980; Inagaki, 1987; Senuma et al., 1990) because the constraint condition in the crystal rotation is different in the vicinity of grain boundaries an'd inside the grain (McLean, 1957). In the vicinity of grain boundaries, many slip systems are active to keep the compatibility of deformation with neighboring grains while inside the grain, the constraint is weakened and the deformation occurs using fewer slip systems.

Considering these phenomena, a model calculation was carried out. In the present calculation, the crystal was rotated according to the pancake model (Raphanel and van Houtte, 1985), in which any shear strain on the plane parallel to the rolling plane is relaxed from any constraint condition and active slip systems are maximum 3, until the distance of grain boundary plane parallel to the rolling direction becomes $28 \mu \mathrm{m}$ because the deformation is assumed to proceed less influenced by the constraint caused by neighboring grains. Subsequently, the crystal rotation was calculated after the lath model (Raphanel and van Houtte, 1985) which is evaluated to predict the rolling texture best (Van Schlippenbach et al., 1986).

Figure 16 shows the plus and minus regions derived by subtraction of the calculation result of the fine grain Material B from that of the coarse grain Material A. Here, the quantity of the intensity was not intentionally given since the quantity changes strongly depending on given assumptions and in this analysis, a qualitative statement is important.

In this calculation, the initial orientations were 648 orientations chosen from relatively homogeneously distributed 36 planar orientations $\{h k l\}$ with 18 directions rotated around $\mathrm{ND} / /\langle h k l\rangle$ with an interval of $10^{\circ}$. The calculation result describes the feature of the difference in the rolling texture between the coarse and fine grain Materials A and B even though some differences are recognized in a detailed comparison. As seen here, the grain refinement of hot bands influences the rolling texture by changing the deformation mode depending on the intensity of the constraint of deformation due to grain boundaries. 


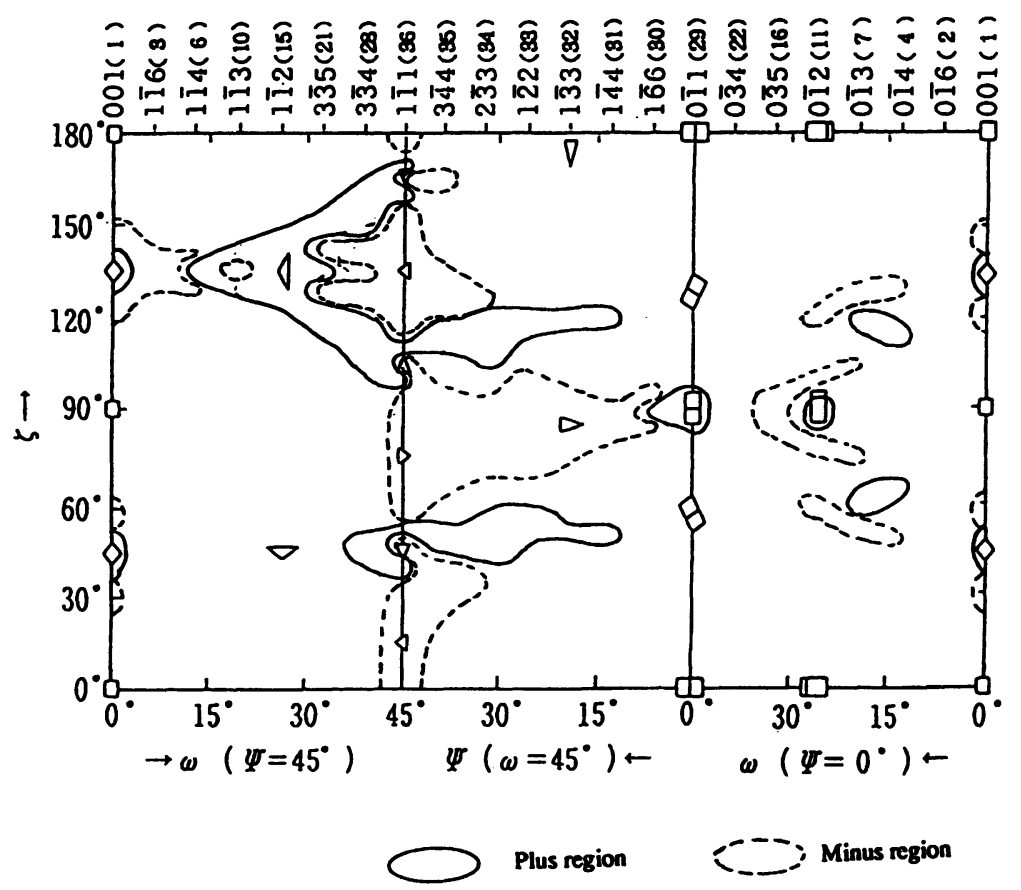

FIGURE 16 Plus and minus regions of the difference in orientation intensities of the rolling textures calculated as: [rolling texture calculated by the lath model after $80 \%$ ] - [rolling texture calculated by the pancake model until $50 \%$ and subsequently by the lath model up to $80 \%$ ].

\section{Influence of the Grain Refinement of Hot Band and the Cold Rolling Reduction on the Formation of Recrystallization Texture}

The change of texture due to recrystallization is characterized by an increase in the intensity of $\gamma$-fiber and a decrease in that of $\alpha$-fiber. The increase in $\{111\}\langle 112\rangle$ is larger than that in $\{111\}\langle 110\rangle$ with increasing cold rolling reduction. In other words, $\{111\}\langle 110\rangle$ is the main orientation of recrystallization texture at lower cold rolling reductions and at $90 \%$ reduction, the main orientation changes to $\{111\}\langle 112\rangle$. This phenomenon will be discussed from the viewpoint of nucleation and growth theory.

The sum of the shear strains needed to carry out the deformation and crystal rotation of a grain due to the rolling deformation can be calculated by a crystal rotation model. The result corresponds to the 
stored strain energy of the deformed grain. According to the calculation, the stored energy of a grain with $\{111\}\langle 110\rangle$ is higher than that with $\{111\}\langle 112\rangle$. After the high energy block theory (Cahn, 1949) that a grain possessing a higher stored energy recrystallizes more easily, $\{111\}\langle 110\rangle$ becomes the main orientation of the recrystallization texture with high possibility if the formation of the recrystallization texture is controlled mainly by the nucleation process.

On the other hand, there is a relationship of a crystal rotation between $\{111\}\langle 112\rangle$ and $\{112\}\langle 110\rangle$ which is the main orientation of the rolling texture around $\langle 110\rangle$ axis existing in the plane perpendicular to the rolling plane including the rolling direction and inclining $60^{\circ}$ from the rolling direction. It is known that a grain boundary between the two grains with this relationship migrates rapidly (Ibe and Lücke, 1968). Therefore, $\{111\}\langle 112\rangle$ becomes the main orientation of the recrystallization texture with high probability if the formation of the recrystallization texture is controlled mainly by the growth process (Senuma and Kawasaki, 1994; Kestens and Jonas, 1996). In the case of a lower cold rolling reduction, the formation of $\{112\}\langle 110\rangle$ in the rolling texture controlling the development of $\{111\}\langle 112\rangle$ through the growth process is relatively weak and $\{111\}\langle 110\rangle$ becomes the main orientation of the recrystallization texture due to a high stored energy.

On the other hand, if the rolling reduction increases, $\{112\}\langle 110\rangle$ develops markedly in the rolling texture as seen in Fig. 10, $\{111\}\langle 112\rangle$ preferentially develops due to recrystallization through the growth process even if the grain of $\{111\}\langle 112\rangle$ is nucleated later than that of $\{111\}\langle 110\rangle$. The development of $\{111\}\langle 112\rangle$ is supported by the fact that the intensity of $\{111\}\langle 112\rangle$ in the rolling texture increases more with increasing rolling reduction in comparison with $\{111\}\langle 110\}$.

The influence of the grain refinement of hot bands on the formation of the recrystallization texture is partially explained by the phenomenon that the grain refinement leads to a similar effect on the formation of the rolling texture as the increase in rolling reduction does. Figure 17 supports the above-mentioned statement showing the change in the intensity of the recrystallization texture for Material B during an increase in the reduction from $80 \%$ to $90 \%$ and the difference in the intensity of the recrystallization texture of Material B from that of Material A in case of the $\mathbf{9 0 \%}$ reduction. Comparing the results, some similarity is recognized. 

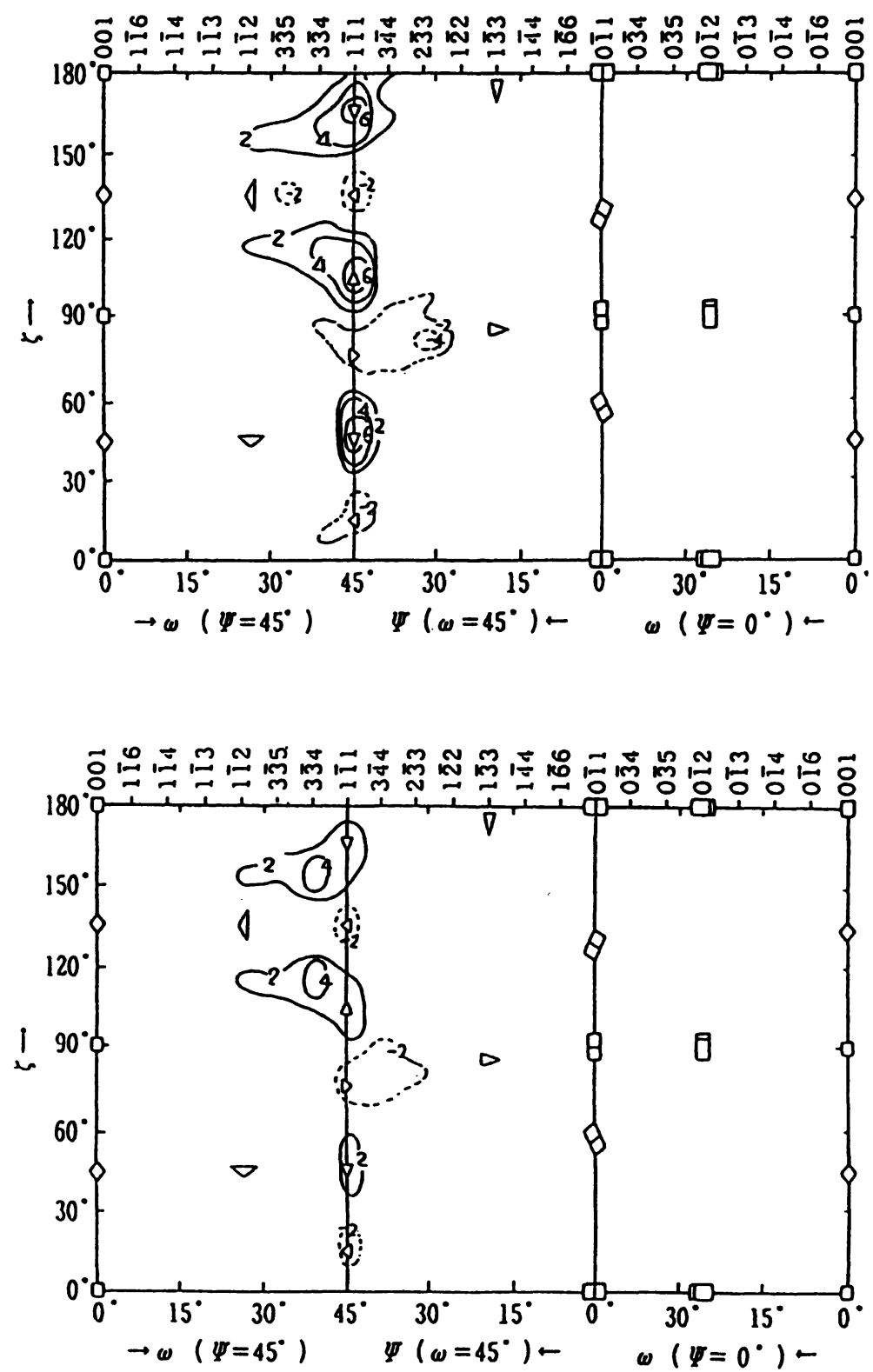

FIGURE 17 Difference of orientation intensities of the recrystallization textures calculated as: [intensity of Material B (fine) rolled to $90 \%$ - that rolled to $85 \%$ ] (above); [intensity of Material B rolled to $90 \%$ - that of Material A rolled to $90 \%$ ] (below). 
The grain refinement of hot bands also influences the formation of the recrystallization texture through the increase in the density of grain boundaries. This influence will be clarified by a detailed study on microscale texture at nucleation sites of recrystallization. The study is going on and the result will be reported in the near future.

\section{Influence of the Cold Rolling Reduction and the Grain Refinement of Hot Bands on the Planar Anisotropy of $r$-values of Cold Rolled and Annealed Sheets}

As seen in Figs. 6-8, the anisotropy of $r$-value of PELC steel is reduced by increasing the cold rolling reduction and by grain refinement of hot band. The mechanism of this phenomenon is then discussed using the mathematical model developed earlier (Senuma et al., 1987) for calculating $r$-values from a texture data obtained from a three-dimensional analysis. In the model, a pencil glide model (Dillarmore and Katoh, 1974) is used as a crystal rotation model.

For the textural analysis, the planar orientations are divided into 36 blocks numbered as shown in Fig. 2. $r$-values were then calculated using the data for one or a group of planar orientations whose intensities significantly changed due to increase in the cold reduction or the grain refinement of hot bands.

Figure 18 shows calculated $r$-values of Materials A and B cold rolled to $80 \%$ and $90 \%$, respectively. Comparing the experimental results in Figs. 6 and 7, it is recognized that the characteristic of the measured anisotropy of $r$-values can be predicted by the calculation.

Figure 19 shows $r$-values calculated with the data for one or a group of planar orientations in the cases of Materials A and B cold rolled to $80 \%$ and $90 \%$, respectively. The planar orientation group $Y$ consists of blocks of numbers $11,16,22,23,29,30$ and 31 including $\{110\}$. The results show that Block Nos. 33, 34 and 35 including $\{221\},\{332\}$ and $\{443\}$, respectively, cause a strong V-type planar anisotropy of $r$-values. As seen in the recrystallization texture in Fig. 13, the reason seems to lie in a strong development of $\mathrm{RD} / /\langle 110\rangle$ in the planar orientations. The intensity of these planar orientations of $\mathrm{RD} / /\langle 110\rangle$ is higher in the sequence of Material B cold rolled to $90 \%<$ Material A cold rolled to $90 \%<$ Material B cold rolled to $80 \%<$ Material A cold rolled to $80 \%$, which coincides with the amount of planar anisotropy of $r$-values as 


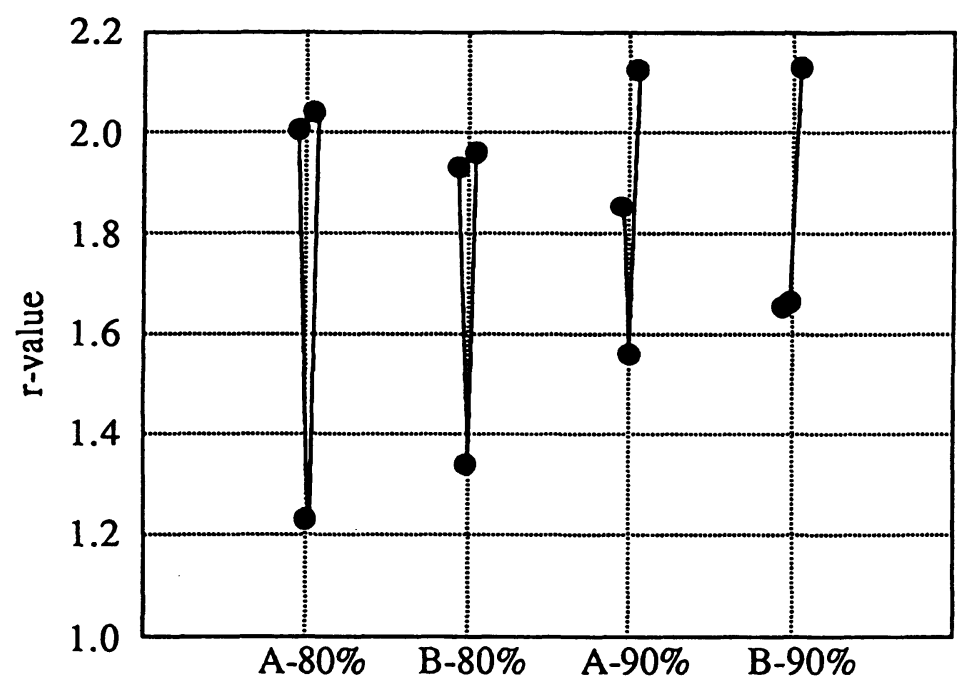

FIGURE $18 r$-values calculated from the recrystallization textures of Materials A and $B$ cold rolled at reductions of $80 \%$ and $90 \%$.

(a)

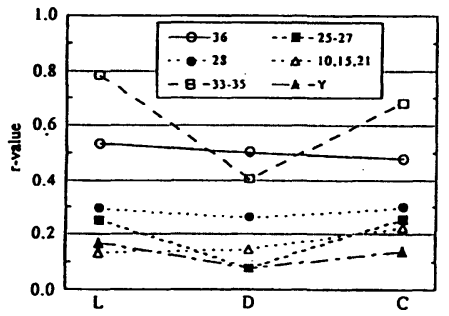

(c)

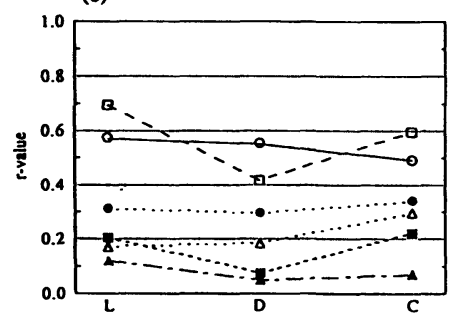

(b)

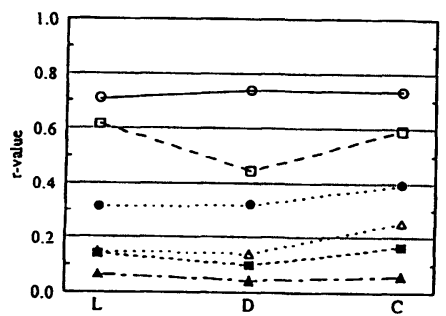

(d)

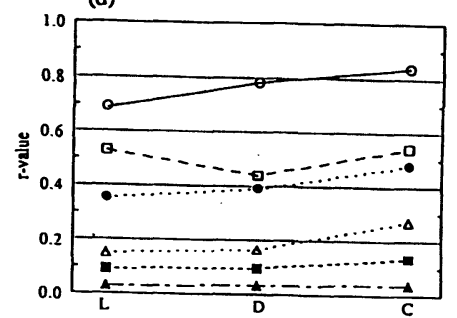

FIGURE $19 r$-values calculated from various orientation groups of a recrystallization texture. (a) Material A cold rolled at a reduction of $80 \%$, (b) Material A cold rolled at a reduction of $90 \%$, (c) Material $\mathrm{B}$ cold rolled at a reduction of $80 \%$, (d) Material B cold rolled at a reduction of $90 \%$. 
seen in Figs. 6 and 7. These findings agree with the result of Hutchinson and Lindh (1994) that the larger planar anisotropy of $r$-values of PELC steel sheet in comparison with that of a Ti bearing extralow-carbon steel sheet is caused by a strong development of $\{332\}\langle 110\rangle$. Although they could not separate the influence of grain refinement of hot band and mere addition of $\mathrm{Ti}$ on the formation of $\{332\}\langle 110\rangle$, the present result using the same steel clearly shows that the intensity increase of $\{332\}\langle 110\rangle$ is caused by grain coarsening of hot band.

Block Nos. 25, 26 and 27 and the group of blocks Y also shows Vtype of planar anisotropy of $r$-values but the quantity is essentially small. $r$-values calculated from Blocks 10,15 and 21 including $\{113\}$, $\{112\}$ and $\{335\}$, respectively, are hardly affected by the grain refinement of hot bands and the cold rolling reduction. High $r$-values and relatively low planar anisotropy of $r$-values are derived from Block Nos. 28 and 36 including $\{334\}$ and $\{111\}$.

Taking an example of Material B cold rolled to $80 \%$ and $90 \%$, the relationship between the planar anisotropy of $r$-values and the texture was investigated in detail. Figure 20 shows the intensities of orientations obtained from a subtraction of the intensities of the recrystallization texture of the $80 \%$ reduction from that of the $90 \%$. The orientations surrounded by a solid line develop more in the recrystallization texture of the specimen cold rolled to $90 \%$ while those surrounded by a dotted line develop less. Due to the increase in the cold reduction from $80 \%$ to $90 \%$, the intensity of most of the $\gamma$-fiber increases, especially $\{111\}\langle 112\rangle$ while $\{111\}\langle 110\rangle$ decreases. This change in the intensity of $\{111\}$ leads to the $r$-value rise in the sequence of $r_{\mathrm{L}}<r_{\mathrm{D}}<r_{\mathrm{C}}$ as seen in Fig. 19. The planar orientation of $\{334\}$ in which the intensity of $\langle 110\rangle \pm 20^{\circ}$ remarkably increases and that of $\langle 110\rangle$ decreases with increasing cold rolling reduction influences the $r$-values in the same way as $\{111\}$ does. Through the decrease in the intensity of $\{443\},\{332\}$ and $\{221\}$, mainly $\langle 110\rangle$ direction, $r_{\mathrm{L}}$ significantly drops and $r_{\mathrm{C}}$ decreases by around half the value while $r_{\mathrm{D}}$ increases a little.

The obtained result indicates that the development of $\mathrm{RD} / /\langle 110\rangle$ of $\{111\},\{443\},\{332\}$ and $\{221\}$ is responsible for the large $V$-type planar anisotropy of $r$-values. It was found that the development of $\{111\}\langle 112\rangle$ contributed to the reduction of the planar anisotropy of the cold rolled PELC steel sheet. This means, as mentioned in the previous section, the formation of the recrystallization texture controlled by the 


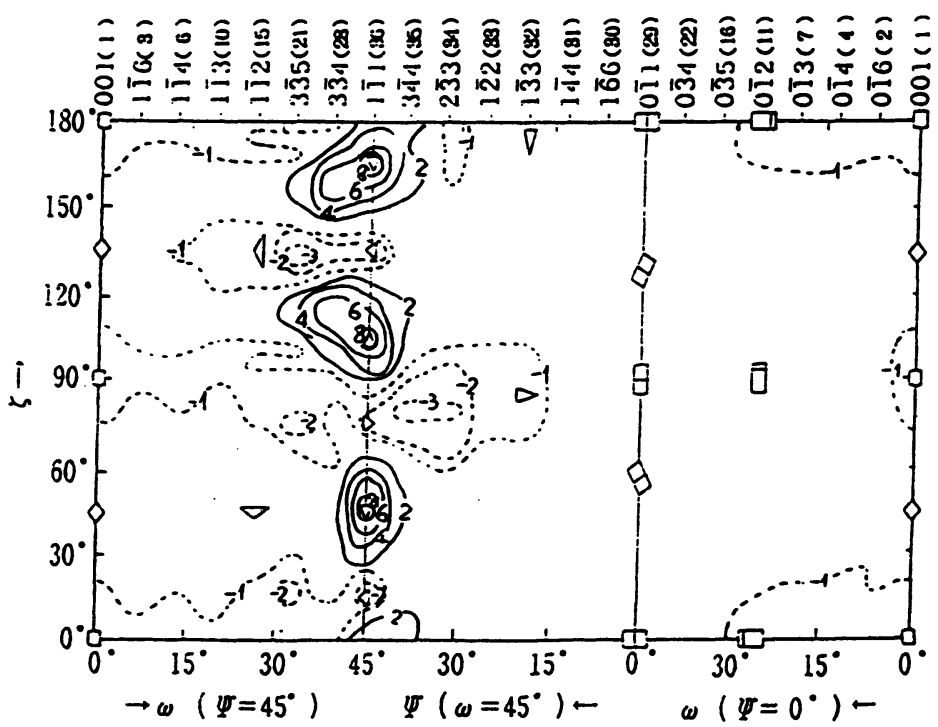

FIGURE 20 Difference of the intensity of the orientations of the recrystallization texture of Material B cold rolled at a reduction of $80 \%$ from that at a reduction of $90 \%$.

growth mechanism instead of the nucleation mechanism leads to the reduction of V-type planar anisotropy of $r$-values.

\section{Measure for the Improvement of $r$-values}

This study shows how the grain refinement of hot bands and increasing the cold reduction contribute to the improvement of $r$-values of cold rolled and annealed PELC steel sheets. Combining the grain refinement of hot bands and increasing the cold reduction markedly improves the weak point of the PELC steel sheets such as a low $r_{\mathrm{D}}$ and a large planar anisotropy of $r$-values causing an inhomogeneous thickness distribution during the deep drawing and consequently leading to the occurrence of breakage or wrinkle of a product. For example, a PELC steel sheet cold rolled from a hot band with a grain size of $54 \mu \mathrm{m}$ to $80 \%$ reveals an $r$-value of 1.2 and a $\Delta r$ of 1.2. Reducing the grain size of the hot band to half the value and increasing the cold reduction up to $90 \%$, a PELC steel sheet with excellent deep drawability, an $r$-value of 1.85 and $\Delta r$ of 0.22 can be obtained. 


\section{CONCLUSION}

Using hot bands of 28 and $54 \mu \mathrm{m}$ in grain size, the influence of the grain refinement of hot bands and cold rolling reduction on $r$-values and the texture formation of cold rolled plain extra low carbon steel sheets has been investigated and the following results obtained:

1. The grain refinement of a hot band leads to a similar effect on the formation of the rolling and recrystallization texture as an increase in cold rolling reduction.

2. The main orientation of the recrystallization texture is around $\{111\}\langle 110\rangle$ in a range of the cold rolling reduction from $70 \%$ to $85 \%$ and changes to $\{111\}\langle 112\rangle$ by increasing the rolling reduction to $90 \%$. The change in the main orientation from $\{111\}\langle 110\rangle$ to $\{111\}\langle 112\rangle$ indicates the transition of the main recrystallization mechanism from nucleation control to growth control. The grain refinement of hot bands shifts this transition to lower cold rolling reduction.

3. Using a mathematical model for calculating $r$-values from a texture, the influence of planar orientation groups on the planar anisotropy of $r$-values was investigated and it was found that a large V-type planar anisotropy of $r$-values was formed by the development of $\mathrm{RD} / /\langle 110\rangle$ in the planar orientation groups of $\{111\}-\{443\}-\{332\}-\{221\}$. The intensity of these orientations decreases due to the grain refinement of hot bands and the increase in the rolling reduction and as a result $r_{\mathrm{L}}$ and $r_{\mathrm{C}}$ decrease while $r_{\mathrm{D}}$ hardly changes and consequently, the planar anisotropy of $r$-values decreases. The development of $\{111\}$ and $\{334\}$ through the grain refinement of hot bands and the increase in rolling reduction increases $r$-values in a sequence of $r_{C}>r_{D}>r_{L}$ and improves the planar anisotropy of $r$-values as whole.

4. The planar orientation $\{110\}$ developed in the recrystallization texture hardly influences the planar anisotropy of $r$-values since its intensity is low.

5. Through the grain refinement of hot band from 54 to $28 \mu \mathrm{m}$ and the increase in the rolling reduction from $80 \%$ to $90 \%, r_{\min }\left(r_{\mathrm{D}}\right)$ improves by $0.7-1.88$ and $r_{\max }-r_{\min }$ decreases from 1.24 to 0.39 . By a proper combination of grain refinement of hot band and increase in the cold rolling reduction, a PELC steel sheet reveals the feature of an excellent deep drawing steel sheet. 


\section{Acknowledgement}

The author thanks Mr. M. Kameda for assistance in the production of hot bands used in the experiment. He also thanks Dr. H. Katoh, Dr. M. Abe, Dr. O. Akisue and Dr. K. Ushioda of Nippon Steel Corporation for useful discussions.

\section{References}

Abe, M., Kokobu, Y., Hayashi, M. and Hayami, T. (1980). Effect of initial grain boundaries on the cold-rolling and annealing textures of pure iron. Trans. Japan Inst. Metal, 44, 84-94.

Cahn, R.W. (1949). Recrystallization of single crystals after plastic bending. J. Inst. Met., 76, $121-143$.

Dillarmore, L.I. and Katoh, H. (1974). A comparison of the observed and predicted deformation textures in cubic metals. Met. Sci., 8, 21-27.

Emren, F., von Schlippenbach, U. and Lücke, K. (1986). Investigation of the development of the recrystallization textures in deep drawing steels by ODF analysis. Acta metall., 34, 2105-2117.

Hutchinson, B. and Lindh, E. (1994). Evolution of texture and anisotropy during recrystallization of IF steels. Proceedings of Int. Forum for Physical Metallurgy of IF Steels, 127-139 [ISIJ].

Ibe, G. and Lücke, K. (1968). Correlations of orientation during the recrystallization of single crystals of an iron-silicon alloy containing $3 \% \mathrm{Si}$. Archiv fuer das Eisenhuettenwesen, 39, 693-703.

Inagaki, H. (1987). Nucleation of a $\{111\}$ recrystallized grain at the grain boundary of cold rolled polycrystalline iron. Trans. JIM, 28, 251-259.

Inagaki, H. (1991). Effect of initial grain sizes on the development of rolling and recrystallization textures in polycrystalline iron. $Z$. Metallkde, 82, 265-274.

Kameda, M., Sanagi, S., Senuma, T. and Furuno, Y. (1993). Effect of hot rolling and cooling conditions on the refinement of hot rolled extra low carbon steel sheets. CAMP-ISIJ, 6, 761.

Kestens, L. and Jonas, J.J. (1996). Modeling texture change during the static recrystallization of interstitial free steels. Metall. Mater. Trans. A, 27, 155-164.

McLean, D. (1957). Grain Boundaries in Metals, The Clarendon Press, Oxford.

Matsudo, K. and Shimomura, T. (1970). Effect of carbon content on deep drawability of rimmed steel sheet. Trans. ISIJ, 10, 448-456.

Matsuo, M., Hayami, S. and Nagashima, S. (1971). A study of recrystallization texture formation in cold rolled iron sheets with X-ray diffraction techniques. Adv. in X-Ray Analysis, Plenum Press, New York, Vol. 14, pp. 214-230.

Raphanel, J.L. and van Houtte, P. (1985). Simulation of the rolling textures of B.C.C. metals by means of the relaxed Taylor theory. Acta metall., 33, 1481-1488.

Ruer, D. and Baro, R. (1977). J. Appl. Cryst., 10, 458.

Senuma, T., Yada, H., Matsumura, Y. and Yamada, K. (1987). Texture formation of Ti-added extra low carbon sheet steels hot-rolled below Ar3 transformation temperature. Tetsu to Hagane, 73, 1598-1605.

Senuma, T., Yada, H., Shimizu, R. and Harase, J. (1990). Texture of low carbon and titanium bearing extra low carbon steel sheets hot rolled below their Ar3 temperature. Acta Metall. Mater. 38, 2673-2681.

Senuma, T. and Kawasaki, K. (1994).Texture formation in Ti-bearing IF steel sheets throughout the rolling and annealing processes in terms of the influence of hot rolling conditions on deep drawability. ISIJ International., 34, 51-60. 
Shimizu, R., Ohta, K. and Harase, J. (1989). An improvement of vector method by allocation of intensities based on the crystallographic symmetry. Textures Microstruct. 10, 101-109.

Taylor, G.I.J. (1938). Plastic strain in metals. Inst. Met., 72, 307-324.

Von Schlippenbach, U., Emren, F. and Lücke, K. (1986). Investigation of the development of the cold rolling texture in deep drawing steels by ODF-analysis. Acta Metall., 34, 1289-1301. 